\title{
Pre-post Case Study of the Psycho Physiological Effects of Ujjayi Breathing on Covid-19 and Hypothyroidism
}

\section{Rashmi A Bapat* and Tanvi Londhe}

Assistant Professor, S-vyasa Yoga University, Bangalore, India

*Corresponding Author: Rashmi A Bapat, Assistant Professor, S-vyasa Yoga

University, Bangalore, India.
Received: September 13, 2021

Published: September 23, 2021

(C) All rights are reserved by Rashmi A Bapat and Tanvi Londhe.

\begin{abstract}
63 participants from Maharashtra, Pune, India between 18 to 70 years of age participated in the intervention group, while 49 were in the control group. In the experimental group, there were four participants diagnosed with covid-19 and five more diagnosed with hypothyroid ailments. A 40-day online intervention was conducted for the intervention group as 25-minute daily sessions of AUM chanting and Ujjayi breathing. Questionnaires about psychological health parameters were answered by both groups before and after the intervention. Participants also recorded their pulse rate and respiratory rate before and after the intervention. A highly significant effect of Ujjayi breathing was observed on perceived stress, anxiety, pulse and respiratory score for intervention group, when compared with the control group. Overall quality of life showed less significant impact.
\end{abstract}

Keywords: Ujjayi breathing; Covid-19; Hypothyroidism

\section{Introduction}

A common man, working professional, retired person or even a homemaker faces a lot of troubles and tensions, one after another. The stress often leads to fearful and negative thoughts which in turn, leading to anxiety. If not handled carefully, the reaction towards an unforeseen problem can affect one's health. In such a case, one may find it unbearable to cope with such stress and anxiety of day-to-day meet. Psycho physiological disorders are physical disorders with psychological overlays [30].

One of the effective ways to reduce this is to adopt yoga as a lifestyle [29]. Yoga aids in reducing the speed of thoughts in one's mind using yogasanas, pranayama and meditation. Once this lifestyle is adopted, one can face the stressful situations in day-to-day life with a lot more confidence and a lot less anxiety. This trans- formation can help to contemplate over the solution of a problem rather than to be bogged down by it.

The problems one might face in extreme stress include high blood pressure, increased pulse rate, irritable bowels, sleep disturbances, depression, hormonal changes, and acidity among many others.

Stress is a feeling of physical or emotional tension. It is body's reaction to a challenge. Stress can trigger what is known as 'fightor-flight response' within the body. When triggered incorrectly for too long, it may cause severe damage to the body. Ideally, once the threat passes, the body should relax back to its natural state.

Stress is caused not by the situation but by our response towards it. As per Yoga Vasishta, stress and yoga are the subject of Yoga as 
'Adhijavyadhi' i.e., bodily disease (Vyadhi) born out of (ja) mental unrest. At the occurrence of a stressful situation, sympathetic system within the body tries to mitigate the response of the external event, whereas the parasympathetic system is activated to balance the changes caused by the sympathetic system. If stress persists continually in the body, the balance between and sympathetic and the parasympathetic system can no longer be maintained. This imbalance begins in the physical body. Constant and frequent disturbances at mind level then percolate the stress into prana body or vital sheath existence, thereby disturbing the breath pattern of the person. If this process continues and this Adhi percolates further into the physical body, there by forms as cause for any disorder or as Vyadhi. However, this percolation can be avoided at the mental body or sheath of intellect body either by breath control or cessation of mind (Patanjal yoga sutra Samadhi pad-1), Pranayama and intelligently followed health habits (Panchakoshaviveka-Taittariya Upanishad). In other words, by following Shreyas (what one should do for one's well-being) against Preyas (what one likes to do but may not be in the best interest of one's well-being), Vyadhi can be avoided.

It was observed through many research and studies on yoga that integrated approach of yoga-asanas, Pranayama, meditation and $\mathrm{OM}$ chanting improve mind control, thereby bringing about relaxation to the body-mind complex. An effective way to slow down the breath is Pranayama, one of the aspects of which is Kumbhaka. There are eight Kumbhakas in total - Suryabhedana, Ujjayi, Sitkari, Sheetali, Bhastrika, Bhraamari, Moorcha and Plavini.

Hatha Yoga Pradipika: The Light on Hatha Yoga', that overall effects of any pranayama are tranquillizing. These practices pacify the body and mind. They simultaneously increase the pranic flow and arouse awareness of the subtle vibration of energy. When the prana is balanced, mind calms down. The discriminating power is restored and well directed, thereby achieving overall wellbeing.

Ujjayipranayama is done with a constriction of the glottis. One must take a feeling of the breath at the throat. A hissing or snoring sound is produced at the throat region [14]. This sound is सस्वन (not created artificially), produced by friction of air with the inner lining of the throat is heard only by the one performing Ujjayi. A well-practised Ujjayi Pranayama detaches the doer from all other thoughts including positive and negative thoughts, thus developing pointed awareness. When one's mind becomes relaxed, calm, and stable, one can take better decisions in adverse situations as well. By performing Ujjayi breathing, random negativity in thoughts is lowered and we can better redirect to constructive thoughts.

Ujjayi has an additional benefit with respect to increasing productivity and managing stressful situations, which prevent one from the urge to multitask. It is known that the human brain is usually incapable of multitasking in the true sense [5]. What gives the illusion of multitasking is more accurately described as switchtasking, where the individual switches their attention from one task to another rapidly. Switch-tasking is usually detrimental because it has three major negative consequences - it leads to longer finishing time, more mistakes and increased stress levels. If in case of such stressful situations, one takes a few minutes to concentrate on Ujjayi breathing, it helps improve their concentration and clarity of thoughts, which lead to better prioritizations and efficient work.

A layman in his busy daily schedule and tensions may not be able to do perform Ujjayi Pranayama to its full extent. So, by going from difficult to easy but proper way, only Ujjayi breathing is taken into the scope of this study.

As stated in classical yoga texts like Hatha yogpradeepika controlling over (Prana) the vital force is an extremely tedious process which requires alertness, awareness and a lot of patience and consistency. So, there is a need for a safe process of Pranayama which is simple, understandable and practicable. If such a process is discovered, it will not remain limited to classroom studies and will be adopted by a wide cross-section of the society. Since Ujjayi breathing does not necessitate dedicated time or a rigorous training to perform, it is easier to adopt in one's daily routine. Thus, it is important to study the physiological and psychological effects of Ujjayi breathing on lifestyle changes.

Method

\section{Participants}

63 participants, male and female, of the age between 18 years to 70 years were in the Ujjayi intervention group. 49 participants, male and female, of the age between 18 to 70 years were in the control group. In the experimental group, there are four covid-19 affected and five hypothyroid cases. 


\section{Materials}

Following 3 questionnaires were distributed to all participants to both groups electronically via Google Forms.

- Perceived Stress Scale (PSS): By Sheldon Cohen, This questionnaire contains 10 questions regarding perception of stressful situations.

- State Trait Anxiety Inventory (STAI): Developed by Charles Speilburger, This questionnaire contains 20 questions about the anxiety perceived by the participants.

Procedure

An online intervention was carried out using Google Meet video conferencing application for 40 days excluding Sundays for $25 \mathrm{~min}$ utes daily. The format of the daily session was as follows:

- Starting prayer in a sitting position of any comfortable posture like Sukhasana,Vajrasana,Padmasana or sitting in a chair
- Eleven times omkara chanting

- Ujjayi breathing for 15 minutes, performed by focusing the awareness at the throat region to feel the nada (hissing or snoring sound).

- $\quad$ Sitting quietly for two minutes

- Closing prayer -Chanting of the Shanti mantra, which is a prayer for universal peace.

The control group was not taught Ujjayi breathing. Questionnaires described above were distributed to participants from both the groups before and after the intervention.

\section{Data extraction}

Data was extracted among all the cases only for Covid -19 and hypothyroid cases. Then it was assessed into excel sheets and statistical analysis was carried out using standard formulas.

Results

Covid $\mathbf{- 1 9}$ and hypothyroid cases

\begin{tabular}{|l|c|c|c|c|c|c|c|c|c|}
\hline $\begin{array}{l}\text { Sr } \\
\text { No }\end{array}$ & \multirow{2}{*}{ Gender } & \multicolumn{2}{|c|}{ STAI } & \multicolumn{2}{c|}{ PSS } & \multicolumn{2}{c|}{ Pulse } & \multicolumn{2}{c|}{ RR } \\
\hline & M/F & Before & After & Before & After & Before & After & Before & After \\
\hline & Mean & 34 & 27.5 & 16.25 & 12.25 & 80.75 & 77.75 & 15.5 & 12.75 \\
\hline & SD & 9.6263 & 4.78 & 3.5939 & 5.678 & 9.9121 & 9.535 & 1.7320 & 1.5 \\
\hline $\begin{array}{l}\text { Percentage } \\
\text { Improvement }\end{array}$ & \multicolumn{2}{|c|}{$* * 18.38$} & \multicolumn{2}{|c|}{24.62} & & $* 3.72$ & & $* * 17.74$ \\
\hline
\end{tabular}

Table 1: Covid -19 cases result.

Hypothyroid patients

\begin{tabular}{|l|c|c|c|c|c|c|c|c|c|}
\hline \multirow{2}{*}{$\begin{array}{l}\text { Sr } \\
\text { No }\end{array}$} & \multirow{2}{*}{ Gender } & \multicolumn{2}{|c|}{ STAI } & \multicolumn{2}{c|}{ PSS } & \multicolumn{2}{c|}{ Pulse } & \multicolumn{2}{c|}{ RR } \\
\hline & M/F & Before & After & Before & After & Before & After & Before & After \\
\hline & Mean & 29.2 & 25.6 & 14.2 & 8.2 & 82.2 & 77.6 & 15.2 & 12.4 \\
\hline & SD & 7.155 & 6.024 & 3.9623 & 5.35 & 9.4180 & 7.829 & 3.4928 & 1.816 \\
\hline $\begin{array}{l}\text { Percentage } \\
\text { Improvement }\end{array}$ & \multicolumn{2}{|c|}{$* 12.33$} & \multicolumn{2}{|c|}{$* * 42.25$} & & $* 5.60$ & & $* * 18.42$ \\
\hline
\end{tabular}

Table 2

** Highly significant,

*significant 
Table 1 ujjayi breathing practices show significant improvement (18.38\% for STAI and $17.74 \%$ for RR). Also, these practices are very safe and useful to reduce anxiety, perceived stress, respiratory rate and there by improvement in physiological functions.

Table 2 ujjayi Breathing Practices show significant improvement (42.25\% for PSS and $18.42 \%$ for RR) to reduce anxiety, stress and respiratory rate.

\section{Discussion}

The effect of Ujjayi Pranayama on various health parameters has previously been studied [9-11], that Ujjayi breathing has a positive effect on stress relief, anger management and fatigue reduction, thereby achieving holistic well-being.

This signifies that Ujjayi breathing intervention had an extremely significant positive impact in reducing stress, anxiety and improving breath control, which improve overall health.

Compared to the aforementioned parameters, a less significant impact of Ujjayi breathing was observed on improving overall quality of life of an individual. In this case, although the result was positive, the difference of effect between intervention and control groups was less prominent than that of others. This can be attributed to the duration and timing of the intervention. A parameter as broad as quality of life may not be altered by a noticeable amount within duration as small as the intervention span. Moreover, the COVID-19 pandemic going on during the intervention may also have affected the mentality of the participants to some extent. As the results show a positive trend nonetheless, further study can be carried out for longer durations and within more normalized social conditions, going into a detailed study of Ujjayi breathing and overall quality of life.

There were some parameters of concern noticed during the intervention. An on-line group intervention relied heavily on availability of continuous and stable internet connections, which may cause logistical problems in some cases. Moreover, due to the unavailability of in-person connections, some important health parameters, which play a key role in the physiological health, such as blood pressure, thyroid and blood sugar levels, needed to be excluded from the study.
Some of these factors can easily be eliminated and this study can be effectively extended in the future. Especially in the light of such promising positive results on psycho-physiological health parameters, physiological indicators like blood pressure, thyroid levels and SPO2 levels also need to be incorporated and the effect of Ujjayi breathing on these parameters can be studied. As Ujjayi breathing can be incorporated with many routine activities, effect of performing Ujjayi breathing while walking needs to be analyzed with precision instruments. Since Ujjayi breathing has been found to be effective in reducing stress and anxiety, it may also generate a positive effect on improving sleep quality and reducing insomnia.

\section{Conclusion}

Ujjayi breathing practices are very safe and effective in reducing increased anxiety, perceived stress and respiratory rate during covid- 19 pandemic situations and for hypothyroid cases.

\section{Authors Note}

The research was carried out to assess the impact of regular Ujjayi breathing on psycho-physiological health on a broad spectrum of people across all walks and stages of life.

\section{Bibliography}

1. Amin A., et al. "Beneficial effects of OM chanting on depression, anxiety, stress and cognition in elderly women with hypertension". Indian Journal of Clinical Anatomy and Physiology 3.3 (2016): 253-255.

2. Ayyangar B K S. "Pranayamadipika". Oriental Longman Limited (2001).

3. Belsare K V. "Upanishadancha Abhyas" (2nd ed) Tridal Prakashana (2003).

4. C M S., et al. "Effect of short-term Pranayama on perceived stress, sleep quality, heart rate and blood pressure". International Journal of Physiology 7.2 (2019): 111-115.

5. Crenshaw D. "The Myth of Multitasking: How "Doing it all" gets nothing done". 2nded, Mango Media (2021).

6. Devkule VG. Gherand Samhita (subodh Marathi bhashantar) M/s SharadaSahitya (2005).

7. Devkule VG. Hathapradipika (subodh Marathi bhashantar) M/s SharadaSahitya. 
8. Dr Agashe S. "Yoga Darshana with reference to Vyasabhash" (1sted) MorayaPrakashan (2021).

9. Dr. Gore MM. "Sharirvidyana ani yogabhyas" (6th ed) Continental Prakashana (2010).

10. Saraswati SS. “Asana Pranayama Mudra Bandha” (4th ed). Yoga Publication Trust (2012).

11. Lathadevi GV., et al. "Modulation of cardiovascular response after Ujjayi Pranayama and Shavasana training in normal human volunteers". Journal of Clinical and Diagnostic Research 6.4 (2012): 571-573.

12. Dr JainV and Dr Sharma J. "Effect of yogic intervention: Pranayama on stress". International Journal of Science and Consciousness 3.2 (2017): 10-16.

13. Sharma KK., et al. "Effect of Yoga therapy on lung functions in respiratory disorder subjects". European Scientific Journal, edition 10. 4.6 (2014): 1857-7881.

14. Singh T N., et al. "Effect of Ujjayi pranayama on selected physiological variables on school girls of Chandigarh". International Journal of Physiology, Nutrition and Physical Education 3.2 (2018): 1211-1213.

15. Gawali S R and Dhule S S. "Effect of Yoga on Anxiety Levels in Working Women". International Journal of Science and Research (IJSR) 2.12 (2013): 2319-7064.

16. Gurjar A A., et al. "Analysis of acoustic of "OM" chats to study its effect on nervous system". International Journal of Computer Science and Network Security 9.1 (2009): 363-367.

17. Harne B P., et al. "Survey on Om Meditation: Its Effects on the Human Body and Om Meditation as a Tool for Stress Management". Psychological Thought 12.1 (2019): 1- 11.

18. Karmakar K and Gaurav Pant. "Effect of yoga program on quality of life of old age people". International Journal of Recent Scientific Research 7.4 (2016).

19. Lathadevi G V., et al. "Modulation of cardiovascular response after Ujjayi Pranayama and Shavasana training in normal human volunteers". Journal of Clinical and Diagnostic Research 6.4 (2012): 571-573.
20. Mahour J and Varma P. "Effect of Ujjayi pranayama on cardiovascular automatic function tests". National Journal of Physiology, Pharmacy and Pharmacology 7.4 (2016): 391-395.

21. Mason H., et al. "Cardiovascular and respiratory effect of yogic slow breathing in the yoga beginner: What is the best approach?" Hindawi Publishing Corporation Evidence-Based Complementary and Alternative Medicine 7 (2013).

22. Metri K., et al. "Pre-post study of efficacy of Aum chanting on insomnia in elderly urban female population of Thane city". International Journal of Womens Health and Gynecology 2.1 (2020): 114.

23. Mohan M., et al. "Cardiorespiratatory changes during Savitri Pranayam and Shavasan". The Yoga Review 3.1 (1983).

24. Muktibodhananda S. "Hatha Yoga Pradipika: The Light on Hatha Yoga" (4th edition (2012) Yoga Publication Trust (1985).

25. Nimbalkar P S. Manahswasthyache PrabhaviSadhan: Pranayam (4th ed) YogVidya Niketan (2016).

26. Nimbalkar Y S. ArogyasathiYog (23rded) YogVidyaNiketan (2016).

27. Prabhupada S. Bhagvad-gita as it is (13thed) The Bhaktivedanta Book Trust (2019).

28. Raghuraj P., et al. "Effect of two selected yogic breathing techniques on heart rate variability". Indian Journal of Physiology and Pharmacology 42.4 (1998): 467-472.

29. Rampalliwar S., et al. "Reduction of cardiovascular hyper reactivity after 12 week practice of Ujjayi pranayam and shavasan in adult human volunteers". International Journal of Current Research 8.8 (2016): 36041-36045.

30. Sansone R A. "Physo physiological disorders and pain medication prescription among internal medicine outpatients". Psychiatry 7.2 (2010): 13-14.

31. Saraswati S. S. "Asana Pranayama Mudra Bandha (4thed)". Yoga Publication Trust (2012).

32. Subramanian V., et al. "Neurohemodynamic correlates of 'OM' chanting: A pilot functional magnetic resonance imaging study Bengaluru". International Journal of Yoga 4.1 (2011): 3-6. 
33. Sürücü C E., et al. "The effects of six-week slow, controlled breathing exercises on heart rate variability in physically active, healthy individuals". Pedagogy of Physical Culture and Sports 25.1 (2021): 4-9.

34. SVYASA DDE Yoga Philosophy and Health MST 104.

35. S-VYASA Yoga University Directorate of Distance Education MSP302.

36. Telles S., et al. "Breathing through a particular nostril can alter metabolism and autonomic activities". Indian Journal of Physiology and Pharmacology 38 (1994): 133-133.

37. Telles S., et al. "Autonomic changes during "om" ditation". Indian Journal of Physiology and Pharmacology 39.4 (1995): 418-420.

38. Tomar R and Singh N. "Effect of Ujjayi Pranayama on selected physiological variables". Science, Movement and Health 29 code CNCSIS category B+11.1 (2011): 201.

39. Vasu SC. Gheranda Samhita, Shri Satguru Publication (1979).

40. Vivekananda S. "Yoga Sutra Patanjal" (1sted) Teenage Publishers (2017).

41. West D. 10 Meditations for inner peace and happiness (2008).

\section{Volume 3 Issue 10 October 2021}

(C) All rights are reserved by Rashmi A Bapat and Tanvi Londhe. 